\title{
Do We Need to Distance Ourselves from the Distance Concept? Why Home and Host Country Context Might Matter More Than (Cultural) Distance
}

\author{
Anne-Wil Harzing ${ }^{1}$ Markus Pudelko
}

Received: 10 March 2015/Revised: 7 April 2015/Accepted: 15 September 2015/

Published online: 28 October 2015

(C) Springer-Verlag Berlin Heidelberg 2015

\begin{abstract}
We scrutinize the explanatory power of one of the key concepts in International Business: the concept of (cultural) distance. Here we focus on its effect on entry mode choice, one of the most researched fields in international business strategy. Our findings might, however, be equally be relevant for the field of International Business as a whole. Our analysis is based on a review of 92 prior studies on entry mode choice, as well as an empirical investigation in over 800 subsidiaries of MNCs, covering nine host and fifteen home countries across the world. We conclude that the explanatory power of distance is highly limited once home and host country context are accounted for, and that any significant effects of cultural distance on entry mode choice might simply be caused by inadequate sampling. Entry mode studies in particular, and International Business research in general, would do well to reconsider its fascination with distance measures, and instead, focus first and foremost on differences in home and host country context. We argue that serious engagement with deep contextualization is necessary in International Business research to pose new and relevant questions and develop new and innovative theories that explain empirical phenomena.
\end{abstract}

Keywords Cultural distance $\cdot$ Entry mode choice $\cdot$ International business $\cdot$ Home country $\cdot$ Host country

Anne-Wil Harzing

anne@harzing.com

1 Middlesex University Business School, London, UK

2 Department of International Business, Tübingen University, Tübingen, Germany 


\section{Introduction}

The fascination of International Business researchers with the (cultural) distance concept can hardly be overstated. Shenkar (2001, p. 519) affirms "Few constructs have gained broader acceptance in the international business literature than cultural distance". Cho and Padmanabhan (2005, p. 309) state that "almost... no international business study can be complete unless there is an explicit variable controlling for cultural distance”. Finally, Zaheer et al. (2012, p. 19) proclaim: "Essentially, international management is management of distance". In this article we critically investigate whether the widespread reliance on the concept of (cultural) distance in International Business research is appropriate. Furthermore, we suggest that the simultaneous neglect of home and host country context might in fact hinder the field's progress and potential.

Previous contributions have already espoused many limitations of the (cultural) distance concept (see, for example, Shenkar 2001; Harzing 2003; Tung and Verbeke 2010; Zaheer et al. 2012). Whereas we concur with their concerns, the purpose of our study is not to add to this prior line of research and outline yet further conceptual weaknesses. Instead we empirically review and test the explanatory power of the cultural distance concept. It is on this basis that we question its usefulness as one of the main concepts in International Business research, and suggest an alternative approach: a focus on context, in particular home and host country context.

Our contribution is based on two pillars: an analysis of the literature and a comprehensive empirical study. We focus on cultural distance, the most frequently used distance concept, which measures the extent to which two national cultures are similar or different. Furthermore, in order to allow for a rigorous investigation, we limit our study to the effects of cultural distance on entry mode choice. Entry mode choice is arguably the concept that has most frequently been connected to (cultural) distance and, in addition, has been one of the most researched fields in International Business Strategy (Werner 2002). However, although we refer to entry mode choice in our empirical investigation, we are not interested in adding yet another (overview) study on this topic, but instead use entry mode choice as an example for our investigation of the relevance of the cultural distance concept. As we will outline in more detail in the discussion, our key arguments are equally relevant for the field of International Business as a whole.

The inclusion of cultural distance as an explanatory or control variable has become almost compulsory in entry mode studies. Nearly all studies in this field used the Kogut and Singh (1988) measure of cultural distance. This metric has been subject to trenchant criticism in Shenkar's (2001) JIBS decade award-winning article: "It masks serious problems in conceptualization and measurement, from unsupported hidden assumptions to questionable methodological properties, undermining the validity of the construct and challenging its theoretical role and application" (Shenkar 2001, p. 520). Harzing (2003) documented the concept's particular problems in the field of entry mode choice, arguing researchers in this field suffer from myopia and systematically overestimate the impact of cultural distance. However, in spite of these and several other critical voices, the popularity 
of cultural distance as an explanatory variable seems unassailable. Citations to Kogut and Singh (1988) continue to increase, in fact half of the article's current, nearly 1500, Web of Science citations occurred since 2010.

The tenacity with which entry mode researchers cling to this conceptualization of cultural distance is even more noteworthy given the contradictory results of their studies. Even the field's four meta-analyses report contradictory findings: two indicate non-significant results (Tihanyi et al. 2005; Morschett et al. 2010), whereas the remaining two (Zhao et al. 2004; Magnusson et al. 2008) report a negative impact of cultural distance on equity based (i.e., high control) entry mode choices. However, one of these indicates this is true only for US firms (Zhao et al. 2004), whilst the other reports the conclusion is valid only for European firms (Magnusson et al. 2008). These contradictory results they have even spawned a number of articles (e.g., Brouthers and Brouthers 2001; Wang and Schaan 2008) that have as their aim to explain this paradox.

The findings of our literature analysis and empirical investigation lead us to conclude that these contradictory results cannot be "explained away" by, for example, the inclusion of specific moderators, but are likely to result from flawed research designs. More specifically, we suggest that they can be traced to differences in sample composition and specific home country or host country differences, such as ownership restrictions, which were not made explicit in these studies. Consequently, we posit that neglecting the home and host country sample composition in entry mode studies, and most likely in other areas of International Business research, has led researchers to inappropriately attribute causality to cultural distance in studies where specific characteristics of the home or host country context are in fact far more likely explanatory factors.

After a review of prior studies that critically investigate the (cultural) distance concept, we present an analysis of more than 90 studies looking at the impact of cultural distance on entry mode choice, the phenomenon we use to illustrate our general arguments. We suggest that, instead of cultural distance, host or home country context characteristics, such as investment restrictions, political risk, economic development, access to capital, or cultural traits (rather than cultural distance) are more likely explanatory factors. Although differences between home or host country context matter, distance is in our view much less important. We then test this assumption by presenting results from our own empirical study covering MNCs in nine host and fifteen home countries across the world. Our findings suggest that cultural distance has little impact on entry mode choice once home and host country control variables are included. Finally, we discuss the implications of our findings, extend our arguments to other areas of International Business research, and present recommendations for International Business research in general.

\section{Previous Debates on the Cultural Distance Concept}

Prior contributions have already espoused a multitude of limitations of the cultural distance concept. So far, however, this critique did very little to affect its popularity. A first, and widely cited, conceptual critique was published by Shenkar (2001) in his 
JIBS decade award-winning article. In this paper, he called for a more rigorous conceptualization and measurement, overcoming the 'illusions' that are at the core of the cultural distance concept and its instrumentation and measurement biases. However, Shenkar does not reject the concept outright. To the contrary, he suggests refinements, such as the inclusion of Long Term Orientation into the Kogut and Singh formula. A stronger critique of the cultural distance concept itself was formulated by Harzing (2003) and subsequently by Kirkman et al. (2006). In these papers, the focus is not on improving the concept, but rather on warning against its inappropriate application.

Ensuing empirical papers by Selmer et al. (2007), Brock et al. (2008) and Lee et al. (2008) deal with specific operationalization problems of the cultural distance concept, such as the 'illusion of symmetry'. Two additional conceptual papers by Shenkar et al. (2008) provide a more pronounced critique of the cultural distance concept itself (in particular Shenkar et al. 2008) and the further development of the closely related cultural friction concept (in particular Luo and Shenkar 2011). Another extensive and widely recognized overview of the shortcomings of the cultural distance concept, and in particular its empirical application, was provided by Tung and Verbeke (2010).

The topical nature of the conceptual critique of what can be called the 'simplistic' (cultural) distance concept and further developments of more 'advanced' distance concepts is also clearly illustrated by a recent special issue of the Journal of International Management (for an overview of contributions see Ambos and Håkanson 2014) and other, very recent, publications. For example, Beugelsdijk et al. $(2014,2015)$ direct our attention toward cultural variation in host countries and demonstrate that their variance-based measure of cultural distance outperforms the mean-based cultural distance measure of the Kogut and Singh index in terms of explanatory power. But ultimately all these, in our view highly valuable, contributions can be subsumed under one maxim: to expose the weaknesses of the cultural distance concept, not with the view to discard the concept, but instead to modify and rectify it in order to ultimately strengthen its essence.

Whereas, despite all criticism, the application of the Kogut and Singh formula in empirical studies continues to grow, this is not the case for the more 'advanced', but also significantly more complex, approaches towards cultural distance. Many of the above mentioned studies are too recent for their conceptualizations to have been adopted by other studies. However, at the time of writing we found 135 publications referring to Shenkar's cultural friction concept (Shenkar et al. 2008) and 143 publications citing the largely prescriptive article by Tung and Verbeke (2010), clearly indicating that the research community perceives these two critical contributions to be very significant. When looking in more detail at each of these 278 publications, we found, however, that only one study has actually applied one of these more 'advanced' forms of cultural distance empirically (Cheok et al. 2013).

In contrast, the vast majority of empirical papers that were either citing Shenkar's cultural friction metaphor or Tung and Verbeke's suggestions only did so in order to highlight the conceptual problems of the Kogut and Singh formula. However, these papers subsequently went on to apply the formula all the same, with reference to its established use in the past. Hence, although the more 'advanced' approaches 
towards cultural distance are recognised, they do not really find any application in empirical work so far. This indicates a clear trade-off between conceptual precision and practical applicability and this trade-off suggests acceptance in theory but not in practice. In practice, researchers continue to apply the Kogut and Singh cultural distance formula, at most paying lip service to its limitations.

Below, we will first review the way this formula has been used in prior studies of entry mode choice. With no less than 30 of the 92 studies published in the last 5 years alone, it is clear that the popularity of this operationalization of cultural distance is unabated in entry mode research. Our review of prior research will show, however, that home and host country context variables provide an equally, if not much more, likely explanation for entry mode choice decisions. Subsequently, we will present the results of an empirical study that tests the explanatory power of cultural distance vis-à-vis home and host country context, and conclude that International Business researchers might do well to refocus on the latter and pay less attention to the former.

\section{Cultural Distance in Entry Mode Choice Studies: An Analysis of the Literature}

\subsection{Methods}

To ensure a comprehensive review of studies using (cultural) distance to explain entry mode choice, we evaluated all publications citing the Kogut and Singh (1988) article, the starting point for most research in this field. We used Google Scholar rather than the Web of Science (also known as ISI) for our search. Google Scholar has a more comprehensive coverage, including not only citations in ISI listed journals, but also citations in books, book chapters, conference and working papers, as well as citations in non-ISI listed journals (Harzing and van der Wal 2008). This resulted in a population of nearly 3500 articles citing the seminal Kogut and Singh (1988) article.

Subsequently, we narrowed down the articles by only including those that had one or more key words relating to entry mode choice in their title, such as for instance: entry mode, joint venture, acquisition, greenfield, equity, franchising and licensing. In addition, we also included all articles that referred to an earlier article exploring the role of cultural distance in entry mode research (Harzing 2003), which included some articles published prior to the Kogut and Singh (1988) article. This left us with a total of nearly 600 references, which were reviewed one by one to establish their relevance for our current paper.

At this stage, only papers that dealt with entry mode choice as a dependent variable were retained. Papers that were deemed not relevant were for instance papers comparing the performance of different entry modes, or papers that looked at the role of culture in the relationship between partners in joint ventures. The end result was a sample of 105 papers, which were coded based on a list of characteristics (see Appendix). Of these, 13 studies could not be included in our review as their measurement and analyses were so unclear that we could not 
adequately assess their results. All 92 papers covered in our literature analysis are marked with a star in the list of references.

\subsection{Results}

The purpose of our analysis is to assess the explanatory power of cultural distance for entry mode choice and, more specifically, whether home and host country context might be more likely explanatory variables. Hence, we have no intention to replicate the excellent reviews of entry mode research (e.g., Brouthers and Hennart 2007), nor to repeat the four meta-analyses in this field. Instead, after a brief review of the key study characteristics, we investigate whether a lack of balanced and comprehensive sampling in terms of home and host countries might have led to inappropriate conclusions regarding the effect of cultural distance on entry mode choice. Subsequently, we review several home and host country contextual factors in detail and argue that they might be more likely explanatory factors for entry mode choice than cultural distance.

\subsubsection{Review of Key Study Characteristics}

Publication Date of Studies and Type of Entry Modes Studied: The 92 studies in our review cover a nearly 30-year period, with the first studies published in 1985 and the last studies published in 2013. Over that period, the number of studies has increased substantially: between 1985 and 1999 only 27 studies were published; between 2000 and 2013 this increased to 54 studies, 30 of which were published in the last 5 years alone. More than half of the studies look at some form of comparison between full and shared control, usually as a choice between a joint venture and wholly owned subsidiary. A quarter of the studies look at equity vs non-equity (e.g., licensing, franchising, exporting, management contracts) entry modes, while the remaining quarter look at the choice between acquisitions and greenfields. Strictly speaking, the latter choice is a choice of establishment mode, not entry mode, but for the purpose of our study the two decisions can be combined. To ensure comparability between studies and drawing on transaction cost theory, we reduced all entry mode decisions to a choice between high and low control modes. Distance is assumed to increase transaction costs, rendering it more difficult for HQ to obtain reliable information and seeking more control. Obviously wholly owned subsidiaries offer more control than joint ventures. In studies comparing non-equity (e.g., licensing and franchising) and equity modes of investment, equity investment was classified as the high control entry mode. In the choice between a greenfield or an acquisition, greenfields normally represent the high control mode, whereas acquisitions represent the low control mode.

Effect of Cultural Distance on Entry Mode Choice: The type of distance measurement in the studies covered in our review is very homogenous. Out of the 92 studies, 82 use the Kogut and Singh (1988) formula to calculate cultural distance, with the remaining ten only referring to the Kogut and Singh study. Of these 82 studies, all use the Hofstede cultural dimensions to calculate cultural distance, with 77 using only this source. Of the ten studies that do not use the Kogut and Singh 
(1988) index, four use country clusters, usually Ronen and Shenkar's (1985) clusters, two operationalize the cultural distance concept as language or another type of distance, three use a perceptual measure of cultural distance, and one does not specify its measurement. The results of these studies for the relationship between cultural distance and entry mode choice are inconsistent to say the least: $35 \%$ of the studies find a positive effect, i.e., higher cultural distance is related to a high control entry mode choice, $31 \%$ find a non-significant effect, and $30 \%$ find a negative effect, with the remaining studies finding a curvilinear result. As mentioned before, the four meta-analyses report equally contradictory results.

Home and Host Countries Included in the Studies: With regard to the home countries covered, the vast majority of studies look at a single home country. The United States (17) and Japan (16) feature most frequently, while the Netherlands (8) and Spain (7) are also popular. The remaining studies are either meta-analyses (4), do not specify the countries included (5) or cover a range of other single home countries. Only 19 studies include multiple home countries. In terms of host countries, the majority of studies (49) include multiple host countries, varying from 4 to 90 countries. For studies looking at single host countries, the most popular host countries are the USA (6), China (4) and Turkey (3). The remaining studies are either meta-analyses (4), do not specify the countries included (9) or cover a range of other single host countries.

\subsubsection{Inadequate Sampling Leading to Design Flaws}

Out of the 92 studies, only 7 studies include both multiple home and multiple host countries, with the remaining 85 studies including either a single home or a single host country. This means that it is entirely possible that, rather than measuring the effect of cultural distance, most studies are merely measuring host or home country differences for those variables influencing entry mode choice. This could be, for example, differential levels of investment restrictions (for host countries) or differences in uncertainty avoidance (for home countries). Consequently, by keeping the home or host country fixed in each comparison, it becomes impossible to separate cultural distance from differences in host or home country context.

Although we are not the first to suggest that home and host country context might be a more likely explanation for entry mode choice than cultural distance (see Slangen and Hennart 2001; Harzing 2003; Maseland and van Hoorn 2013), none of these earlier contributions have pursued this argument in any detail, nor combined a review of prior studies with a large-scale empirical test as we do in this article. Below, we suggest a number of factors for both home and host country context that might be likely explanatory factors for entry mode choice and illustrate how results from the single host or home country studies we reviewed might be reinterpreted in this context. We also review the few studies that included multiple home and host countries in detail and suggest that cultural distance is unlikely to be a major explanatory factor in those studies either. It is important to note that our aim is not to provide the definitive answer to which home or host country context characteristics are most likely to explain entry mode choice. In our view this is 
almost impossible; relevant explanatory factors have to be established on a case-bycase basis and cannot be determined a priori.

\subsubsection{Home Country Context and Entry Mode Choice}

In many, if not all, of the single host country studies we analyzed, home country context characteristics are just as likely, if not more likely, to explain variation in entry mode choice as cultural distance. One set of home country context characteristics that are relevant in explaining variation in entry mode choice might be specific home country cultural traits (rather than cultural distance), such as for instance uncertainty avoidance and short vs long-term orientation. MNCs from a country with a high level of uncertainty avoidance might opt for a greenfield instead of an acquisition investment, as this entry mode allows them to exert a higher degree of control on foreign operations. Similarly, an MNC from a country with a longerterm orientation is likely to value full control (i.e., in a greenfield) more than setting up a foreign operation as quickly as possible. Japan, for example, is a country that is heavily invested in other countries and ranks very high on uncertainty avoidance and long-term orientation. And indeed, its corporations are well known for their strong preference for greenfields over acquisitions (see e.g., Anand and Kogut 1997; Chang and Rosenzweig 2001; Anand and Delios 2002; Kamal 2009). By contrast, many Western countries rank lower on uncertainty avoidance, are more short-term oriented and their MNCs frequently prefer significantly more acquisitions (Anand and Kogut 1997). As MNCs from these home countries often invest in culturally distant countries, cultural distance and home country characteristics with regard to uncertainty avoidance and time orientation will often be significantly correlated, but this does not mean that cultural distance explains entry mode choice.

In addition to cultural context, the home country institutional context might also lead MNCs to prefer acquisitions over greenfields or vice versa. One institutional factor that is likely to be a key determinant of entry mode choice is the (lack of) availability of capital. Wilson (1980), for example, links the relatively strong inclination of British MNCs for acquisitions to their long tradition of operating in a market for corporate control, facilitated by easier access to capital markets. According to his study, $46 \%$ of the entries of British MNCs into foreign markets are acquisitions instead of greenfields, compared to just $9 \%$ for the entries of Japanese MNCs and $28 \%$ for entries of MNCs of other nationalities. Many other studies since have confirmed this pattern for British MNCs (see e.g., Healy and Palepu 1993; Anand and Kogut 1997; Chang and Rosenzweig 2001). Studies comparing the use of acquisitions by home country (see Healy and Palepu 1993) also indicate that any such home country acquisition preference is stable. So any study on entry mode choice that includes only one host country is likely to simply capture differences in ownership preferences-whether culturally or institutionally based-of MNCs of various home countries rather than the effect of cultural distance on entry mode choice.

Kogut and Singh's (1988) original study is a case in point. The authors include 506 entry-mode choices of MNCs from more than 15 home countries investing in the US and find cultural distance to be positively related to a choice for greenfields 
at a 0.10 level of significance. However, two thirds of the MNCs included are Japanese, British or Canadian. Consequently, the established correlation between cultural distance and entry mode choice might well have been found on the basis of differences in home country context. As we have already seen, Japanese MNCs show a significantly higher than average preference for greenfields, whereas British (and Canadian) firms demonstrate a significantly higher than average preference for acquisitions. Kogut and Singh's (1988) conclusion that cultural distance is the cause for their findings can not be upheld unless we investigate entry mode choices of Japanese as well as British and Canadian MNCs in both culturally similar and dissimilar countries.

Many later studies show similarly problematic attributions of causality. For instance the positive effect of cultural distance on joint ventures in the USA in Hennart and Larimo's article (1998) is likely to be a simple difference in ownership preferences between Finnish and Japanese firms, the only two home countries in the study. In Chang and Rosenzweig's study (2001), the positive relationship between cultural distance and greenfield investments in the USA is likely to simply reflect the differential preference for greenfields between Japan, which made up $58 \%$ of the sample, and the various Western home countries included in the study. Although it is by definition impossible to attribute causality in cross-sectional studies, we suggest that home country context is a more likely candidate to explain differences in entry mode choice than cultural distance for any of the single host country studies that we analysed. To reduce our key argument to a single formula: cultural and institutional differences matter more than cultural and institutional distance.

\subsubsection{Host Country Context and Entry Mode Choice}

In many, if not all, of the single home country studies we analysed, host country context characteristics are just as likely, if not more likely, to explain variation in entry mode choice as cultural distance. The following institutional host country context characteristics are likely to be particularly relevant factors to explain entry mode choice: government restrictions, political risk, and economic development. A particularly 'hard factor' that might not even leave an MNC any choice in its entry mode are host government restrictions. Governments can coerce MNCs to form joint ventures with a domestic partner, for example to enforce technology transfer in exchange for market access. China is a prime example for the successful application of this policy (Long 2005). A high degree of political risk, or in more general terms country risk, speaks in favour of low risk entry mode choices such as non-equity or shared control investments (Gatignon and Anderson 1988). A low level of economic development is equally likely to lead to non-equity investments, given the limited market opportunities, and to greenfield investments, due to a lack of acquisition candidates. Home countries, certainly home countries that usually feature in entry mode studies, are frequently from the highly industrialized West. Host countries in Asia, Latin America, Eastern Europe or Africa, that are culturally distant from the Western home countries, are characterized by a high level of government restrictions, a high degree of political risk, and a low level of economic development. As a consequence, institutional host country characteristics such as 
government restrictions, political risk, and economic development are likely to be significantly correlated with cultural distance in most entry mode studies (Harzing 2003). However, we suggest that these specific host country differences are a much more credible explanatory factor for entry mode choice than cultural distance with which they correlate.

This means that in all studies that do not include these and other host country factors as control variables, which is the case for the majority of studies on entry mode choice in our review, ${ }^{1}$ cultural distance is likely to be nothing more than a proxy for factors that really matter, namely host country characteristics such as government restrictions, political risk, and economic development. A representative study in this context is Agarwal's (1994) investigation of 148 entry-mode decisions of US MNCs which finds cultural distance to be positively related to joint ventures. Despite the fact that this study features no less than 20 host countries, more than $40 \%$ of the total sample consists of only three countries: culturally distant Japan, and culturally similar Canada and the UK. The only host country in this study with a significant number of joint ventures is Japan (with more than $80 \%$ of entries into the country being joint ventures). We argue that the dominance of joint ventures as a gateway into Japan might well be entirely unrelated to cultural distance. Instead, a more likely reason for the high level of joint ventures in Japan could be the frequently described difficulty for outsiders to enter the tightly knit domestic distribution channels (see e.g., Czinkota and Kotabe 2000) or even simply complications regarding the acquisition of domestic companies. Even if we were to accept the argument that cultural distance is the cause for the preference for joint ventures in Japan, this rationale does not hold for other host countries in this study. France and Italy, for example, are culturally more distant to the US than Canada and the UK, so US MNCs should be more likely to use joint ventures in these countries than in Canada and the UK. However, the percentage of joint ventures for France and Italy is a mere $13 \%$, whereas for Canada and the UK they are 14 and $20 \%$, respectively.

\subsubsection{Studies with Multiple Home and Host Countries}

There are only seven studies — out of the 92 included in our review - that do include multiple home and host countries. Of these, one features only Scandinavian home countries (Larimo 2003), which have virtually identical scores on Hofstede's dimensions, with host countries including both culturally close Western countries and culturally distant Asian countries. So in terms of cultural distance this is effectively a single home country study that is likely to show the effect of differences in host country contexts, such as investment restrictions in Asian countries, rather than the effect of cultural distance. Another study (Arora and Fosfuri 2000) includes only three home countries/regions with two thirds of the sample composed of the US and Japan. Hence the results are likely to reflect

\footnotetext{
1 The studies that included one or more host country factors found insignificant results for the impact of cultural distance on entry mode choice. For instance, in both Cho and Padmanabhan's (1995) and Erramilli et al.'s (1997) study the significant effect of cultural distance disappeared when a host country dummy, developed vs less developed, was included.
} 
differences in home country context, most likely investment preferences. A third study (Brouthers and Brouthers 2001) includes four Western home countries that score very similarly on Hofstede's dimensions and five Eastern European host countries. Hence, the significant negative relationship between cultural distance and a high control entry mode might well be caused by differences in host country context. We suggest that the Russian and Romanian host country context, i.e., a more volatile different political environment than Hungary, Poland and the Czech Republic, is equally likely to explain the preference for low control entry modes in these countries as their larger cultural difference from Western home countries.

The remaining four multiple home/host country studies all find non-significant results, even though two predicted a positive (Pangarkar and Klein 2001; Harzing 2002) and two a negative (Ackerman 2005; Estrin et al. 2007) relationship between cultural distance and a high control entry mode option. Particularly noteworthy is Pangarkar and Klein's (2001) study as it offers the chance to isolate the effect of cultural distance. This study's sample includes a wide range of Western home and host countries that are quite similar on host country context characteristics such as political risk, economic development and government restrictions, but, at the same time, culturally distant from each other. Hence, their non-significant result for cultural distance supports our suggestion that home or host country context may be a more likely explanatory factor for entry mode choice than cultural distance. In the next section, we present an empirical study that allows us to test this proposition.

\section{Cultural Distance and Entry Mode Choice: An Empirical Analysis}

After our comprehensive analysis of the literature, we will empirically test the explanatory power of cultural distance vis-à-vis home and host country context with regard to entry mode choice. In terms of entry mode choice we are in particular interested in the choice between greenfield and acquisition, where a greenfield investment represents a "high control" entry mode. However, before doing so, we need to first empirically test our arguments that specific characteristics of the home and host country context are likely to be strongly correlated with both entry mode choice and cultural distance, thus leading to inappropriate attributions of causality when only cultural distance is included in empirical studies. In our preceding analysis of the prior literature we identified three home country characteristics (uncertainty avoidance, long-term orientation and access to capital) and three host country characteristics (investment restrictions, political risk and economic development) that might provide equally likely, if not more likely, explanations for entry mode decisions than cultural distance. We also predicted that each of these characteristics would be significantly correlated with cultural distance in any sample that includes both Western and Asian countries. This is because Asian countries are not only culturally distant from Western countries, but also generally have a higher levels of uncertainty avoidance, long-term orientation, political risk, and investment restrictions, as well as a lower level of access to capital and economic development. Thus: 
Hla: High uncertainty avoidance and long-term orientation in the home country will have a significant positive correlation with both greenfield investments and cultural distance; access to capital in the home country will have a significant negative correlation with both greenfield investments and cultural distance.

$H 1 b$ : Investment restrictions and political risk in the host country will have a significant positive correlation with both greenfield investments and cultural distance; economic development in the host country will have a significant negative correlation with both greenfield investments and cultural distance.

Our next, and decisive, step is to investigate the relative importance of cultural distance vis-à-vis home and host country context. First, drawing on the findings of most prior studies (see e.g., Anand and Delios 1997; Harzing 2002), we assume that cultural distance does have a statistically significant positive effect on the likelihood of a greenfield investment if home and host country context is not considered. We further assume that cultural distance does not have a systematic impact on entry mode choice once home and host country context are considered. Hence we formulate the following hypotheses:

H2a: Cultural distance has a significant positive effect on the likelihood of a greenfield investment rather than an acquisition when no home or host country dummies are included.

H2b: Cultural distance has no significant effect on the likelihood of a greenfield investment rather than an acquisition when home and host country dummies are included.

Our empirical study is intended as an empirical test of our general premise, i.e., that home and host country context might be more important explanatory variables of entry mode choice than cultural distance. It is not our intention to provide an extensive theoretical or empirical discussion of which specific home or host county variables might be more appropriate explanatory variables than cultural distance, as this is in our view ultimately a question that has to be answered on a case-by-case basis. However, the single variable that we expect to provide by far the most simple, common sense, and "objective" explanation of entry mode choice is the extent to which host countries restrict foreign ownership of domestic companies. If firms are not allowed by host country governments to go down a certain entry mode route, then this "hard" criterion simply overrides any consideration or entry mode preferences the companies might otherwise have. These restrictions can prevent both wholly owned subsidiaries (when compared to joint ventures) and acquisitions (when compared to greenfields). Unfortunately, however, investment restrictions are not included as a variable in most entry mode studies, even though this is absolutely essential. Hence:

H2c: The inclusion of host country investment restrictions captures a large part of the variance attributed to host countries. 


\subsection{Methods}

\subsubsection{Sample and Data Collection}

Our data were collected through a survey in the (wholly owned) foreign subsidiaries of MNCs headquartered in a wide range of home countries. Subsidiaries were located in nine host countries/regions. A wide range of industries were included, both in services and in manufacturing, with varying levels of global integration, local responsiveness and $\mathrm{R} \& \mathrm{D}$ and advertising intensity, thus allowing us to use industry dummies as a proxy for a range of variables traditionally included as explanatory variables in entry mode studies. Table 1 presents the distribution of our sample across host country, home country and industry. Our sample provides an excellent opportunity to test the effect of (cultural) distance on entry mode choice as it includes a substantial variation in both Asian and Western home and host countries. Within the European region, it also includes countries with very different cultural profiles: Nordic, Germanic, Latin and Anglo. Geographically, it includes countries from all corners of the world, except Africa and Latin America.

Data were collected over a nearly 2-years period (August 2008-April 2010) using both paper and online questionnaires. Questionnaires were mailed locally by one of the researchers through collaboration with local universities, except for France and the Nordic countries, for which questionnaires were mailed from the UK. Reminders were used to increase response rates. We received 817 questionnaires, resulting in an overall response rate of $13.83 \%$ when correcting for undeliverables, a response rate which is quite typical for multi-country studies (Harzing et al. 2013).

\subsubsection{Measurement of Variables}

Our dependent variable, entry mode choice was measured by asking for the type of subsidiary: greenfield (new start-up firm) or acquisition (take-over of existing firm). In order to be able to compare our results with prior entry mode studies, cultural distance was measured using the Kogut and Singh (1988) formula, based on Hofstede's original cultural dimensions: individualism/collectivism, power distance, uncertainty avoidance, and masculinity/femininity.

Home and host country were measured with direct questions ("In which country is the HQ that you report to located?" and "In which country is this subsidiary located?"). Scores for the home country cultural dimensions of uncertainty avoidance and long term orientation were taken from Hofstede (2001). The home country variable "access to capital" and the host country variables "investment restrictions" and "political risk" were all operationalized with questions taken from the IMD world competitiveness report. This report draws on a survey sent yearly to an international panel of experts and asks them to score a series of statements relating international competitiveness on a scale of 1-10. Access to capital was measured as the average of two items ("stock markets provide adequate financing to companies" and "access to foreign capital markets is not restricted for domestic companies"). Regarding investment restrictions and political risk, the items used asked respondents for their opinion on the level of investment restrictions and 
Table 1 Distribution of sample across host country, industry and home country
Number of respondents

Host country

$\begin{array}{lr}\text { Australia/New Zealand } & 92 \\ \text { China } & 91 \\ \text { France } & 70 \\ \text { Germany } & 125 \\ \text { Japan } & 80 \\ \text { Korea } & 118 \\ \text { Nordic countries } & 71 \\ \text { Spain } & 82 \\ \text { United Kingdom } & 88\end{array}$

Industry

Banking and insurance 20

Business services $\quad 78$

Chemicals $\quad 129$

Food and beverages $\quad 55$

Industrial machinery $\quad 130$

Measuring instruments $\quad 30$

Motor vehicles and parts $\quad 138$

Paper and allied products $\quad 33$

Pharmaceuticals $\quad 73$

Rubber and plastics $\quad 60$

Other 71

Total 817

Home country

( $<10$ resp. omitted)

Austria 14

Belgium 14

Denmark 14

France $\quad 67$

Finland 19

Germany 107

Italy 18

Japan $\quad 89$

Netherlands $\quad 35$

Norway 11

Singapore 13

Sweden 28

Switzerland $\quad 42$

United Kingdom $\quad 56$

United States 222

Other 68

$\begin{array}{ll}\text { Total } & 817\end{array}$ 
political risk on a scale of 1 ("foreign investors may not acquire control in a domestic company, risk of political instability is high") to 10 ("foreign investors are free to acquire control in a domestic company, risk of political instability is low"). The final scores were reversed, so that a high score could be interpreted as a high level of investment restrictions and political risk. Our final variable, level of economic development, was measured as GDP per capita so that higher values represent higher economic development.

Ideally we would have liked to use the relevant measures for the year each investment was made. However, this was not possible as IMD data were only available from 1998 or 1999 onwards. As the median for establishment year in our sample was 1996, this is a reasonable approximation, and we thus used 1998/1999 data for all cases.

The first control variable, industry, was measured with a direct question ("in which general industry sector is this subsidiary operating"). Likewise subsidiary age and size (in terms of number of employees) were measured with direct questions: "In which year was this subsidiary established or acquired" and "How many employees work at this subsidiary", whereas the function of the subsidiary was probed by asking the respondent to select any of the following six functions that applied to their subsidiary: R\&D, manufacturing, sales/marketing, distribution/ logistics, service, national/regional HQ. As subsidiary size was badly skewed, we used the natural logarithm of the number of employees as the final measure of size.

\subsubsection{Analytical Method}

Hypotheses $1 \mathrm{a}-\mathrm{b}$ were tested with simple bivariate correlation analyses. In line with previous research, we used binary logistic regression to test our Hypotheses $2 \mathrm{a}-\mathrm{c}$, with our dependent variable coded as 0 for acquisition and 1 for greenfield. A positive and significant estimated coefficient indicates that the variable is associated with an increased probability of a greenfield entry mode. The null hypothesis that all $\beta$ 's are zero can be tested with the model $\chi^{2}$. When the model $\chi^{2}$ is significant, this null hypothesis can be rejected. A test that a specific coefficient is zero can be based on the Wald statistic. Significance levels of coefficients based on the Wald statistic are indicated in the models in Table 3.

Our baseline model includes all the control variables discussed above, with subsequent models adding cultural distance (model 2), home and host country dummies (model 3), and investment restrictions (model 4). The added explanatory power of these models can be assessed through the $\Delta \chi^{2}$ and the increase in pseudo $\mathrm{R}$-square measures (Cox and Snell, and Nagelkerke $\mathrm{R}^{2}$ ). Three of the variables included in our model (industry, home country, host country) are categorical variables. The statistics first show the overall significance of these variables through the Wald statistic. In order to investigate the effect of individual industries, home and host countries on the entry mode choice, we used the deviation method, which shows how each category of the predictor variable except the reference category compares to the overall effect. The reference category for industry and home country was "other", whereas for host country it was Australia/New Zealand. For 
the control variable industry we only report the two industries that were significantly different from the overall effect.

\subsection{Results}

Table 2 reports means, standard deviations and correlations among the variables in the study, including all controls. Data on entry mode was missing for $8.2 \%$ of our cases. Of the remainder, the majority of subsidiaries in our sample $(59.3 \%)$ were acquisitions. With regard to age, one third of the subsidiaries was established or acquired in the 2000s, with another third established or acquired in the 1990s. In terms of size, $70 \%$ of the subsidiaries have between 50 and 500 employees, with the most frequent category in the 101-250 range. However, around $10 \%$ of the subsidiaries employ either less than 50 employees or between 501 and 1000 employees or more than 1000 employees. Greenfield subsidiaries tend to be older and are less likely to have an $\mathrm{R} \& \mathrm{D}$, distribution, or national/regional headquarters (HQ) function.

Cultural distance correlates positively with the likelihood of a greenfield entry mode, which confirms the findings of most prior studies (see e.g., Anand and Delios 1997; Harzing 2002). As predicted in Hypothesis 1a the home country characteristics uncertainty avoidance and long term orientation are significantly positively and access to capital significantly negatively correlated with greenfield investments. Apart from uncertainty avoidance these variables also show the expected significant correlations with cultural distance. Likewise, and as predicted in Hypothesis 1b, investment restrictions and risk of political instability are significantly positively and economic development significantly negatively correlated with greenfield investments as well as cultural distance. The strongest correlations with greenfields and cultural distance are found for investments restrictions $(\mathrm{r}=0.47$ for greenfields, and $r=0.49$ for cultural distance). The latter is virtually identical to the 0.48 correlation found by Slangen and Hennart (2008).

Table 3 provides the regression analyses to test our Hypotheses $2 \mathrm{a}-\mathrm{c}$. In the first step of the regression analysis, we include only the control variables. Subsidiary size and age have a negative and positive effect on the likelihood of a greenfield investment, respectively. In terms of subsidiary functions, subsidiaries with an $\mathrm{R} \& \mathrm{D}$, distribution or national/regional HQ function are less likely to be greenfields. These effects are persistent in most models. In terms of industry, the banking and the motor industry are the only industries with significantly different entry mode patterns when compared to all other industries, with greenfields less likely in banking and more likely in the motor industry.

In model 2, we include cultural distance. As in previous studies, it is shown to have a significantly positive, albeit rather small, effect on greenfield investments. The model statistics show that the addition of cultural distance is significant and provides a very modest increase in the explanatory power of the model. This confirms Hypothesis 2a. In model 3, we include the nine home countries that had more than 10 observations. Japan and Korea were combined, because of the similarity in their profiles, as were the Chinese Asian countries/regions (mainland China, Taiwan Hong Kong, Singapore) and the Nordic countries (Sweden, Norway, 


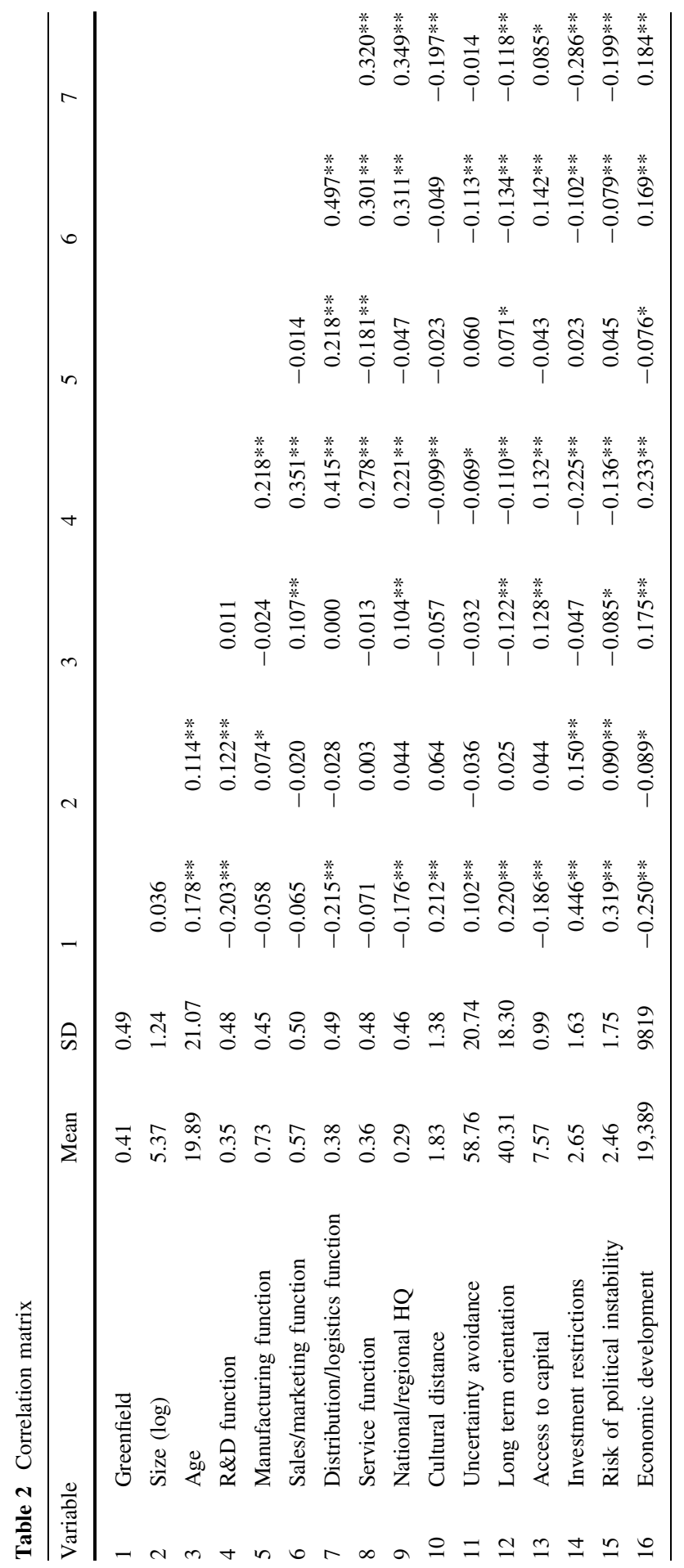




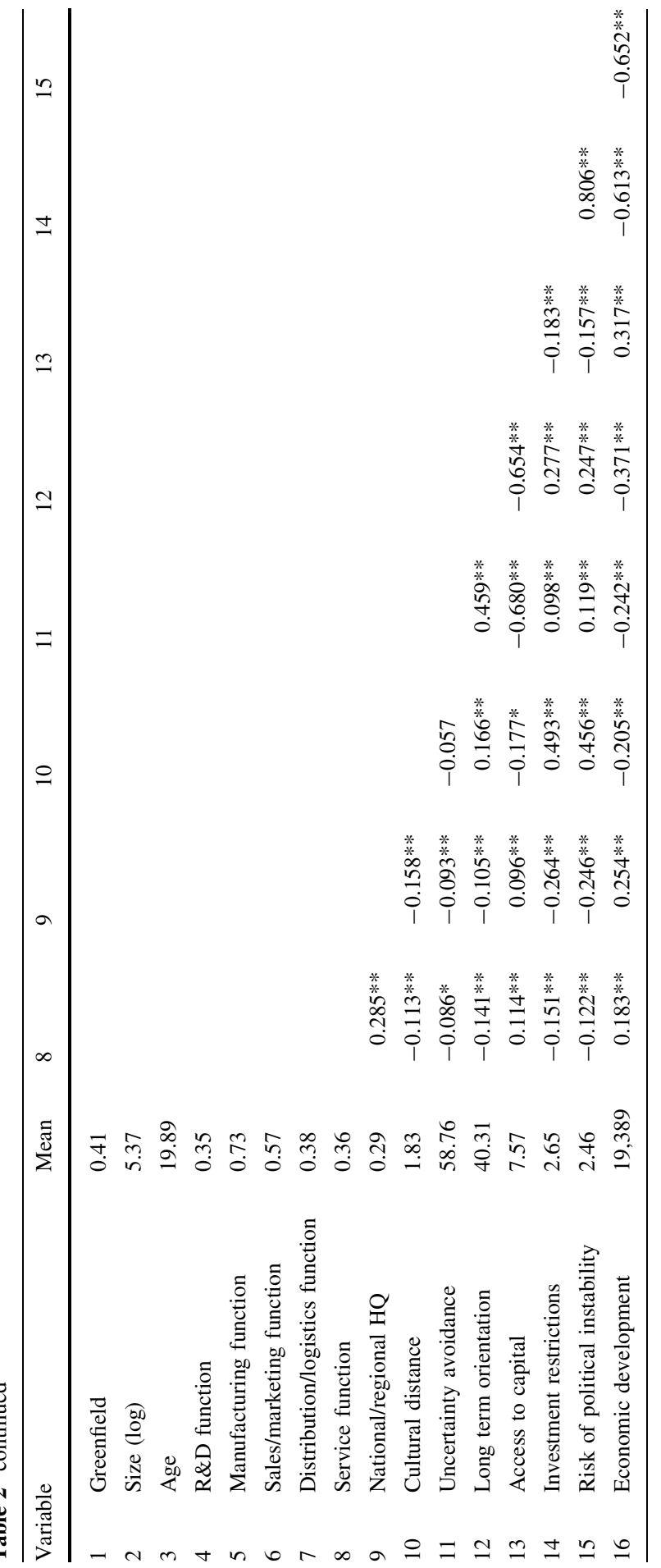




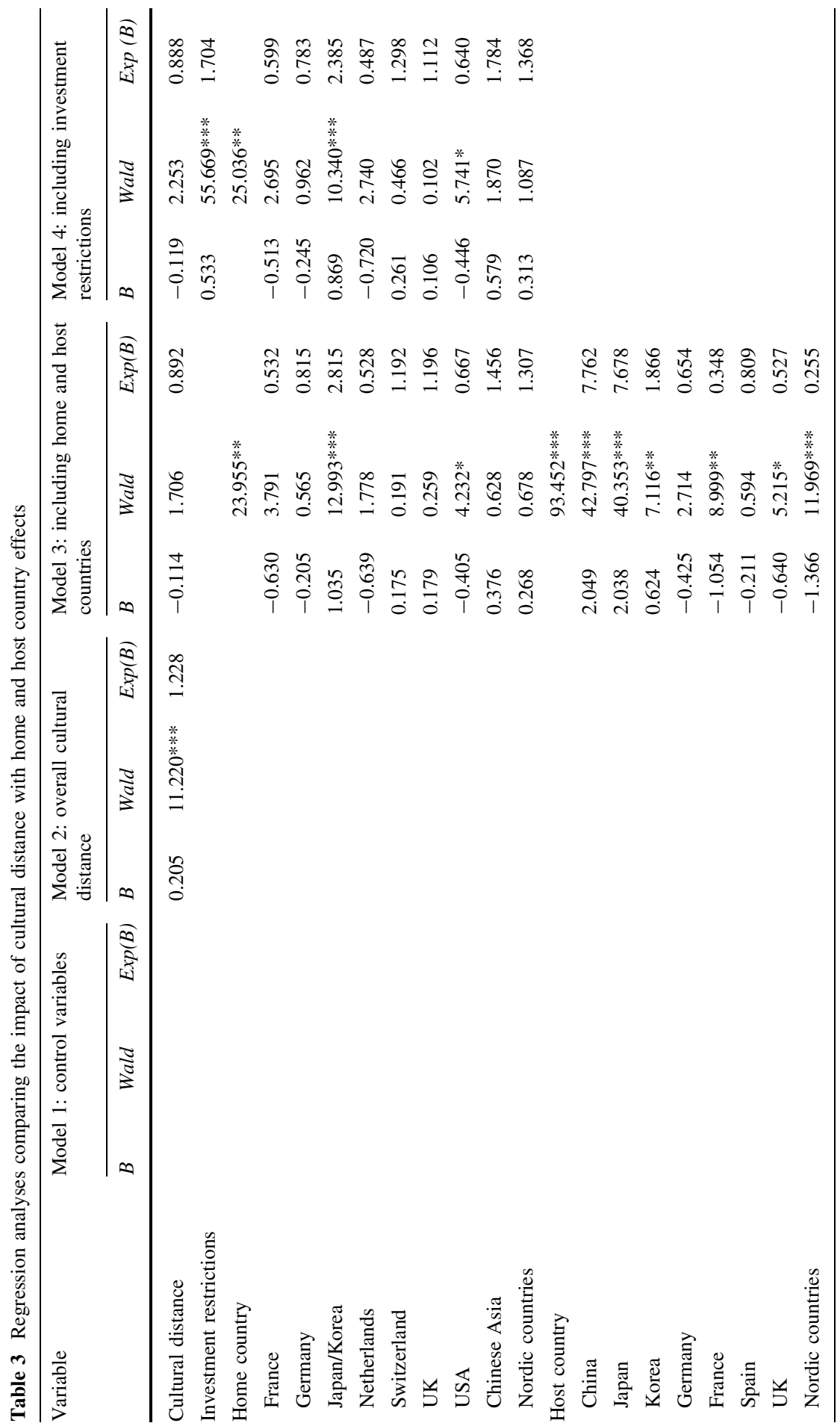




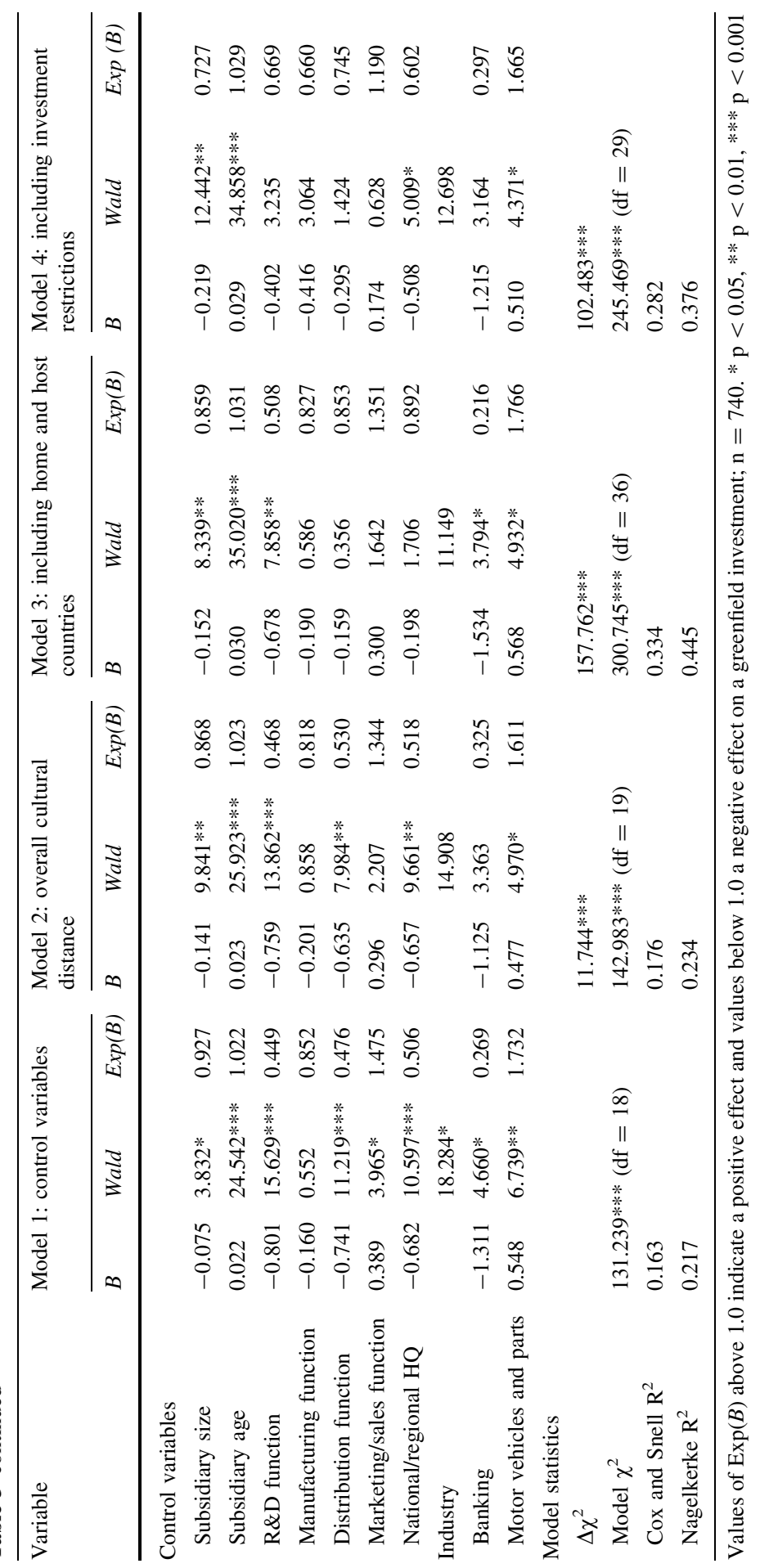


Denmark and Finland). Confirming earlier studies (Hennart and Park 1993; Makino and Neupert 2000; Barkema and Vermeulen 1998; Vermeulen and Barkema 2001) MNCs headquartered in Japan/Korea are more likely to enter countries with a greenfield investment, whereas MNCs headquartered in the USA are more likely to use acquisitions. In terms of host countries, greenfields are significantly more likely in all Asian host countries (China, Japan and Korea) and significantly less likely in France, the UK and the Nordic countries. Overall, there is a clear separation between Asian and Western European host countries.

When home and host countries are included, the cultural distance effect becomes insignificant, thus confirming Hypothesis $2 b$, and even changes its sign. Overall, the inclusion of home and host countries provides a much larger increase in explanatory power than the inclusion of cultural distance in model 2 . The model $\mathrm{R}^{2}$ only increases by $8 \%$ with the inclusion of cultural distance, whereas the inclusion of home and host countries leads to a $105 \%$ increase. Inclusion of home and host countries thus provides an increase in the model's explanatory power that is more than thirteen times as large as for cultural distance.

Model 4 introduces a specific host country variable (investment restrictions) that we argued would capture a large proportion of the variance related to host countries. As Table 3 shows this is very much the case, confirming Hypothesis $2 \mathrm{c}$. Inclusion of the single-item investment restriction variable captures around $60 \%$ of the increase in explanatory power due to host countries. Most importantly, the combination of home country variables and the investment restriction variable explains more than nine times as much variance as cultural distance.

\section{Discussion}

\subsection{Summary of Key Findings}

Our results are based on two entirely different methods: a literature analysis of more than 90 previously published papers and an empirical study in over 800 subsidiaries of MNCs. Our literature analysis revealed that one third of all studies that employed the cultural distance concept to explain entry mode choice found one particular effect, another third the opposite effect and the last third no effect at all. This confusion was mirrored by meta-analyses, which also reported very different results. Reviewing the prior studies in detail, we not only concluded that the cultural distance concept, when based on Kogut and Singh index, is a poor predictor of entry mode choice, but also that studies employing the cultural distance concept as defined by Kogut and Singh are likely to have merely measured home or host country context differences for those factors that really influence entry mode choice. Our correlation analyses showed that a range of home and host country context characteristics do indeed correlate significantly with both cultural distance and entry mode choice (confirming Hypothesis 1a and Hypothesis 1b). We argued that this might have lead to inappropriate attributions of causality in studies that only include cultural distance as an explanatory variable. 
Our multivariate analyses also clearly demonstrated that the ability of the cultural distance concept, as it is applied in most studies to explain entry mode choice, is rather limited. Although our analysis indicated that cultural distance has a very small, but statistically significant positive effect on greenfield investments (confirming Hypothesis 2a), this effect becomes insignificant when including home and countries in our model (confirming Hypothesis 2b). Moreover, the inclusion of home and host countries in our model provided an increase in explanatory power that was more than thirteen times as large as the inclusion of cultural distance. More specifically, investment restrictions, the host country context variable likely to be most directly related to entry mode choice, proved to capture $60 \%$ of the variance attributed to host countries (confirming Hypothesis 2c). Although investment restrictions might seem like a "naïve" or even "simplistic" measure, and not as "sophisticated" as a complex theoretical explanation, it is the single variable that has the most logical and direct relationship to entry mode choice.

\subsection{The Relevance of Home and Host Country Context: Asian vs Western Countries}

Whereas home and host country contexts are by definition country specific, there is an important divide between Asian and Western countries. Greenfields are more common in Asian than in Western host countries regardless of the MNC home country, and greenfields are more common for MNCs headquartered in Asian than in Western home countries regardless of the host country (see Fig. 1).

In the absence of host country variables in the model, any significant impact of (cultural) distance measures on entry mode choice in our sample can easily be explained by the dichotomy between Western and Asian host countries. Subsidiaries in Asian host countries show much larger summated cultural difference scores with their HQ countries than subsidiaries in Western host countries $(t=16.002$, $\mathrm{p}=0.000$ ). We can distinguish a number of underlying contextual reasons for the different entry mode patterns in Asian as opposed to Western home and host countries. First, equity markets in the West tend to be more active and less

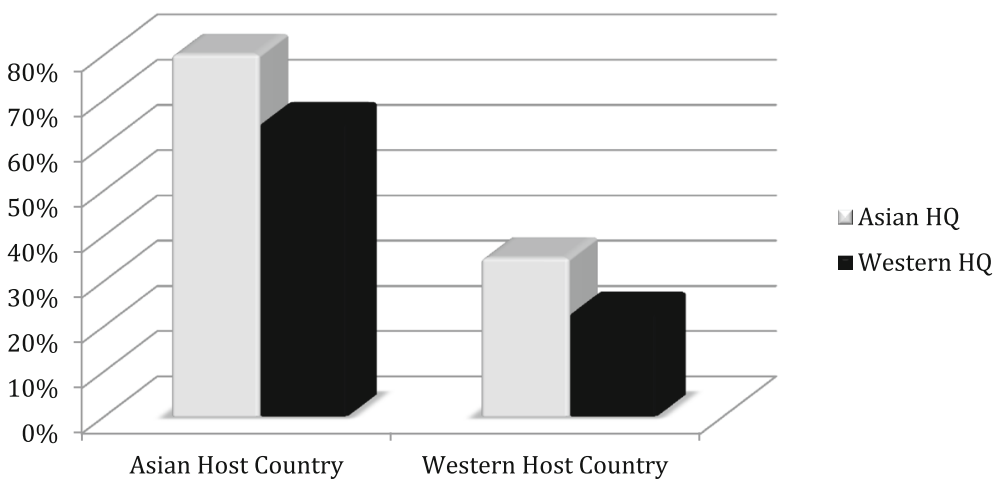

Fig. 1 Percentage of greenfield subsidiaries by home and host region 
restrictive, and characterized by a more dispersed ownership structure, rendering the option of acquiring companies in Western countries more feasible (Slangen and Hennart 2001). This host country contextual difference might have a spill-over effect on home country differences as well. As Asian companies are, due to the institutional difficulties of acquiring companies on their home turf, less used to these transactions, they simply might not have the necessary experience to embark on such acquisitions, even in Western countries where the institutional conditions for such an entry mode strategy are more suitable. Another reason for different entry mode strategies might be linked to the fundamentally different strategies of managing the multinational network. US and European companies often pursue a polycentric strategy that leaves more autonomy for local units. This strategy is well suited for acquired companies that have established corporate cultures and strategies. In contrast, Japanese companies follow a more ethnocentric strategy, which is more standardized around HQ practices (Kopp 1994). Such a focus on HQ practices, however, renders the management of acquired firms more complex, and hence is likely to lead to a preference for greenfields.

In addition to investment restrictions in Asian countries, a number of other host country contextual variables might explain the preference for greenfields in Asian host countries. Companies might prefer entering developing host countries via greenfields, over which they have more control, for example to assure their quality standards (Agosin and Machado 2005; Woodcock et al. 1994). While this argument might hold for China and to some extent for Korea, Japan is of course different as it is a highly developed country. Even so, host country specific cultural and institutional contextual traits (see e.g., Czinkota and Kotabe 2000) might provide a powerful explanation for the greenfield route. Japanese companies adhere to the shareholder philosophy to a much lesser extent than most Western companies and are more concerned about their employees as key stakeholders. Therefore, it becomes essential for management to keep their company independent and to fend off any attempt of being bought up by another company, in particular a foreign one (Pudelko and Mendenhall 2009). Consequently, it is much more difficult for foreign companies to find possible take-over candidates in Japan and, due to these complications, they often prefer to establish greenfields. Similar complications exist in Korea and, even more so, China. These arguments are as valid for culturally distant Western headquarters as for culturally closer headquarters in other Asian countries. In other words, it is not cultural distance that is of relevance here, but the cultural and institutional context in home and in particular host countries.

This detailed explanation of the Asian context demonstrates that we cannot define a priori which specific contextual factors are most relevant with regard to entry mode choice, or any other topic for that matter. Instead, this needs to be considered on a case-by-case basis for each country or region. This also implies that we need to re-emphasise the study of the particularities of country-specific phenomena for International Business research in general. It is regrettable that in International Business research country-specific knowledge appears to be considered subordinate to "universal" theories these days. 


\subsection{Possible Extensions of Our Study on Cultural Distance}

In our study we focused on cultural distance as the most frequently used distance concept. However, what if we broadened our statistical analyses to include, for example, geographical, institutional and language distance? Table 4 summarises the results for these distance variables. Geographical distance, institutional distance (measured as differences in education and differences in political systems), and language distance were modeled after Dow and Karunaratna (2006) and Dow and Larimo (2009). Actual values for all our home/host country pairs were sourced from Douglas Dow. Geographical distance was badly skewed, so we used the natural log for this variable. Apart from geographical distance, that isn't even significant without home/host country controls, each of the distance variables follow exactly the same pattern as cultural distance: their effect is significant without home and host country control, but insignificant when these controls are included.

In addition to looking at different distance dimensions, we also conducted several sensitivity analyses relating to cultural distance. First, we disaggregated the Kogut and Singh index into distance metrics for the individual Hofstede dimensions and found that, when neither home nor host countries were included in the regression analyses, Power Distance had a marginally significant negative effect on the likelihood of greenfields, Uncertainty Avoidance had a significant positive effect, and Individualism and Masculinity had no significant effect. Finding that different cultural dimensions have different (and even partially opposing) effects should have even been more reason to suspect that home/host country effects are at play rather than a cultural distance effect. Second, we reran the regression analyses including the House cultural dimensions. The results for the "should be" dimensions were identical to the Hofstede dimensions: when included without home and host country controls, cultural distance had a significant effect, when home countries and host countries were included the significant effect disappear completely. When using the "as is" cultural dimensions, cultural distance was not significantly related to entry mode choice even without home/host country controls.

A further extension to our study would be to investigate the explanatory power of the distance concept in relation to other phenomena. Previous studies have already related the distance concept, among others, to the transfer of (HR) management practices, the choice between local and expatriate managers, the performance of

Table 4 The impact of geographical, institutional and language distance on entry mode choice

\begin{tabular}{lcccccccc}
\hline Distance variable & \multicolumn{2}{l}{ Without home/host country controls } & & \multicolumn{2}{l}{ With home and host country controls } \\
\cline { 2 - 3 } \cline { 7 - 8 } & Beta & Wald & Significance & & Beta & & Wald & Significance \\
\hline Geographical distance & -0.056 & 1.698 & 0.192 & & -0.004 & 0.004 & 0.996 \\
Political distance & 1.024 & 36.410 & $0.000^{* * *}$ & & -0.395 & 0.900 & 0.674 \\
Educational distance & 0.930 & 19.793 & $0.000^{* * *}$ & & -0.576 & 1.956 & 0.162 \\
Language distance & 0.356 & 16.888 & $0.000^{* * *}$ & & -0.028 & 0.056 & 0.972 \\
\hline
\end{tabular}

$* \mathrm{p}<0.05, * * \mathrm{p}<0.01, * * * \mathrm{p}<0.001$ 
foreign subsidiaries, innovation, organizational transformation and technology transfer. We suggest that our key findings might hold equally for these and other phenomena. For example, we would suggest that the extent to which, say, a British MNC transfers its HRM practices to its German and Polish subsidiaries will be influenced more by host country contextual factors, such as the local labour market regulations, than by (cultural) distance. This implies that even though the cultural distance between the UK and Germany is significantly lower than the distance between the UK and Poland, the potential to transfer HRM practices will not necessarily be higher, because of the highly regulated German labour market.

The main outcome of our current study is thus not a statement on the extent to which (cultural) distance makes a difference. Nor can we, on the basis of our results, speculate to what extent more 'advanced' approaches towards cultural distance, if applied, would have a significantly higher explanatory power than the 'simpler', yet almost exclusively applied, Kogut and Singh index. Instead, we emphasize that any study investigating any distance dimension with reference to any phenomenon and using any approach would need to include several home and host countries (and select them on valid theoretical grounds). As important as this requirement is, almost none of the studies in the field of entry mode choice adhered to this methodological necessity. Consequently, in order to test to what extent (cultural) distance has real explanatory power, we recommend the following: choose a country sample for which (cultural) distance is high (e.g., between Latin European and Nordic countries), but for which fewer differences in other contextual variables such as labour market or investment restrictions exist, for example due to common EU regulations. This would allow us to separate the effect of cultural distance from the effect of home or host country context.

\subsection{Implications of Our Study in the Context of the Current Literature on (Cultural) Distance}

We have shown that the popularity of simplistic measures of cultural distance, such as the Kogut and Singh index, continues to increase, in spite of the conceptual criticism by adherents of more 'advanced' cultural distance concepts. It is therefore important to explore what our empirical results mean for the latter research stream. We have already concluded that many of the suggestions put forward by Shenkar and colleagues, Tung and Verbeke (2010) and others recommend more nuance, differentiation and sensibility towards context. A more systematic focus on context in particular is also our key recommendation. However, we go one step further and argue that no matter how 'advanced' we render the cultural distance concept, sometimes cultural distance (or any other type of distance) has very little explanatory value. Instead, purely contextual factors, such as legal entry mode restrictions, provide an explanation for the observed phenomena that might appear to be simpler or less sophisticated, but ultimately is far more powerful.

We should also point out that by introducing more nuance, differentiation and sensibility towards context, we render the application of the cultural distance concept more complicated and burdensome. Clearly, one of the main reasons for the continued popularity of the Kogut and Singh formula is the ease with which it can 
be applied. Using this simple formula means that scholars are relieved from having to consider a wide range of country-specific contextual factors, and evaluate which might be most relevant for their investigation. All they need to do is enter a few distance measures into their regressions. The more we move towards 'advanced' forms of cultural distance, the more we move away from ease of application. It is therefore no surprise that out of the 278 texts citing either Shenkar's cultural friction concept or Tung and Verbeke's detailed guidelines, only one study has actually applied one of these more 'advanced' forms of cultural distance empirically (Cheok et al. 2013).

Likewise, we don't see a sustainable solution in the development of ever more types of distance, a practice that currently seems to be en vogue. In addition to the more established cultural, psychic, institutional, language and geographic distance, we came across economic, political, governance, legal, educational, technological, knowledge and cognitive distance. Although each of them might bring a new facet to the overall debate, we ultimately concur with Zaheer et al.'s (2012, p. 18) verdict: "Unfortunately, the problems detailed in Shenkar's award-winning critique are not visited solely on cultural distance; they plague other distance constructs as well". In the end all these additional distance concepts are attempts to reduce complex phenomena to "questionable and frankly indefensible proxies" (Shenkar 2012, p. 16).

When compared to authors who focused on developing more 'advanced' approaches of cultural distance, our recommendation is at the same time much simpler and much more radical. Instead of increasing the degree of complexity of the distance concept-making it more reliable conceptually, but also more difficult to apply in practice-we call for a paradigm shift, moving away from theadmittedly conceptually highly seductive-distance concept and instead focusing first and foremost on context. Hence, we propose that a researcher's first call should be to critically consider various home and host country context variables rather than simply assume that (cultural) distance can provide a catchall explanation for all International Business phenomena. Only if home and host country context are duly accounted for and samples are carefully chosen in terms of home and host countries, does it, in our view, make sense to reintroduce distance variables into the equation.

\subsection{The Wider Implications of Our Study for International Business Research}

Although pleas for the relevance of context for International Business research are by no means new (see e.g., Schneider and Barsoux 2003; Redding 2005), most management scholars, even in International Business, have not taken context seriously or have only paid lip service to it. Management scholars, particularly those representing an economics-based strategy perspective, are frequently relying on existing theory and extant data sets that are often a-contextual. The only exception to this might be their reference to the concept of culture, which is usually, however, referred to in its static, reductionist and conveniently employable form of cultural dimensions and their country scores (Brannen and Doz 2010). Consequently, we cannot agree more with scholars such as Shenkar (2004) and Tsui (2007) who 
emphasize the relevance of contextually "rich and thick" data. Contextual information is not only important to better understand a nation's domestic companies or even an entire business system (or several, in a comparative analysis). It is also relevant for studying the exchanges taking place across different contexts, for example the home and host country contexts of MNCs. Hence, we see the major objects of analysis in International Business to be deeply embedded contextually, and it is only through studying and understanding the relevant contexts that we can advance our comprehension and interpretation of International Business phenomena.

Serious engagement with deep contextualization is also necessary in International Business research to pose new and relevant questions, apply existing theories to novel contexts, acknowledge the limitations of existing theories, and develop new and innovative theories that explain empirical phenomena. Ultimately, understanding contextual particularities is essential in order to understand universalities. It is through comparing contextual particularities across different locations that we can identify common phenomena, and separate them from idiosyncratic particularities or even singularities, which ultimately helps us to discover context-free regularities (see also Pudelko 2006).

Studying more path-dependent and embedded combinations and configurations of country-specific context instead of relying on distance-based generalizations also implies a profound difference in terms of underlying theoretical assumptions within International Business research. Whereas the distance concept perceives cultural and institutional distance more as liabilities or constraints, a focus on cultural and institutional contextual differences is open to regard these differences as opportunities or resources. Thus, concentrating on the ability of MNCs to increase competitiveness by combining the advantages of very different national contexts is an entirely different perspective (differences as opportunities) from keeping contextual distance low to reduce transaction costs (distance as liability). Understanding what opportunities and what liabilities are can only be achieved, however, by closely studying particular contextual differences at home and host country locations and not by establishing generic distance measures (Sorge 2005).

Furthermore, in order to gain the required understanding about deeply embedded context, interdisciplinary research, often called for, but rarely conducted in research practice, is an absolute necessity. Whereas psychology has reached a powerful influence in management, matching the weight traditionally accorded to economics, insights from other disciplines such as political science, law, sociology, anthropology and history should (again) be accorded more relevance, especially in International Business research. In addition, instead of relying so heavily on mainly "academic" concepts such as distance, scholars should (again) pay more attention to those concepts, phenomena, facts, and variables that do matter for acting managers. More specifically, most entry mode studies seem to "have succeeded in completely removing the manager(s) who make(s) the entry-mode decision from the equation ... [and as a consequence] no researcher ... ever seems to have bothered to ask managers whether CD was a factor that influenced their entry-mode decisions" (Harzing 2003, p. 103-104). We therefore suggest that scholars should (again) become better listeners, focusing on the actual and context-sensitive problems of 
practitioners, instead of relying overly on abstract and largely context-free conceptualizations.

We acknowledge that these recommendations can be seen as "uncomfortable" and "inconvenient" for International Business researchers. Collecting particularistic, multilevel, contextual data, with a focus on managers' actual problems instead of scholars' preconceived solutions, clearly is more cumbersome than the convenient application of generic distance measures. However, we would argue that, as cumbersome and muddy the pathways of collecting "rich and thick" contextual data might be in comparison to the convenient and neatly paved boulevards of simple distance measures, they can potentially lead to unearthing much deeper insights. In that sense, we urge International Business scholars to exchange their business shoes and high heels for rubber boots and return to the groundwork more commonly practised by prior generations of International Business scholars.

\section{Conclusion}

We believe that our study has made two significant contributions. First, we showed that any study examining the impact of any distance dimension on any empirical phenomenon using any distance-based approach would need to include several carefully chosen home and host countries to be able to differentiate the effect of distance from the effect of home or host country context. Second, we established empirically that home and host country context has a significantly higher explanatory power for entry mode choice, and quite possibly for many other International Business phenomena, than the Kogut and Singh based distance concept. Consequently, we recommend that studies in International Business focus first and foremost on home and host country context and resist the temptation to use (cultural) distance as a catchall concept, thus avoiding an illusion of causality, which ultimately hinders the potential of International Business research to provide useful guidance to managers on key International Business phenomena.

Acknowledgments Part of the research on which this article is based was supported under Australian Research Council's Discovery Projects funding scheme (project DP0555977). The views expressed herein are those of the authors and are not necessarily those of the Australian Research Council.

\section{Appendix: Coding Scheme for Prior Entry Mode Studies}

Authors: Name of authors

Year: Publication year

Journal: Journal the paper was published in.

Dependent variable: What type of entry mode decision was studied? Choice between acquisition or greenfield, between joint venture and wholly owned subsidiary, between licensing and FDI. 
Home/host countries: List of home/host country/ies included in the study. If not listed, recorded as not specified. Also indicates whether any countries make up a significant share of the observations.

Type of data: Were data primary or secondary, how many observations were included, and in what time period were the data collected.

Type of distance studied + measurement: Lists the type of distance included in the study as well as the way this was operationalized.

Hypothesized relationship between distance and level of control: This is usually positive (+ high distance/high control) or negative (- high distance/low control), but distance can also only be included as a control variable (CV) or with a proposed relationship (NR). In a very small number of cases a non-linear relationship is proposed or distance is used as a moderator. However, in that case distance is usually ALSO included as a direct effect.

Empirical results: the statistical results of the study, indicates whether the relationship found was positive $(+)$, negative $(-)$ or non-significant (NS). Also include the significance level ( $\mathrm{p}<0.1, \mathrm{p}<0.05, \mathrm{p}<0.01, \mathrm{p}<0.001$ ).

Final relationship between cultural distance and high control option: summary of relationship for easy comparison: generally positive, negative or NS, and curvilinear in two cases.

Inclusion of country/region dummies in the analysis: Indicates whether countries or regions were included in the regression analysis as dummy variables. Also indicates whether this changed the results if the regression were run with and without dummies.

\section{References}

* Ackerman A. (2005). The effect of the target country's legal environment on the choice of entry mode. Available at SSRN 622822.

* Agarwal, S. (1994). Socio-cultural distance and the choice of joint ventures: a contingency perspective. Journal of International Marketing, 2(2), 63-80.

* Agosin, M., \& Machado, R. (2005). Foreign investment in developing countries: does it crowd in domestic investment? Oxford Development Studies, 33(2), 149-162.

Ambos, B., \& Håkanson, L. (2014). The concept of distance in international management research. Journal of International Management, 20(1), 1-7.

* Anand, J., \& Delios, A. (1997). Location specificity and the transferability of downstream assets to foreign subsidiaries. Journal of International Business Studies, 28(3), 579-603.

Anand, J., \& Delios, A. (2002). Absolute and relative resources as determinants of international acquisitions. Strategic Management Journal, 23(2), 119-134.

Anand, J., \& Kogut, B. (1997). Technological capabilities of countries, firm rivalry and foreign direct investment. Journal of International Business Studies, 28(3), 445-465.

*Arora, A., \& Fosfuri, A. (2000). Wholly owned subsidiary versus technology licensing in the worldwide chemical industry. Journal of International Business Studies, 31(4), 555-572.

* Barkema, H. G., \& Vermeulen, F. (1997). What differences in the cultural backgrounds of partners are detrimental for international joint ventures? Journal of International Business Studies, 28(4), $845-864$.

* Barkema, H. G., \& Vermeulen, F. (1998). International expansion through start-up or acquisition: a learning perspective. Academy of Management Journal, 41(1), 7-26.

* Bell J. (1996). Joint or single venturing? An eclectic approach to foreign entry mode choice. Unpublished PhD Dissertation, Tilburg University. 
Beugelsdijk, S., Maseland, R., Onrust, M., van Hoorn, A., \& Slangen, A. (2015). Cultural distance in international business and management: from mean-based to variance-based measures. The International Journal of Human Resource Management, 26(2), 165-191.

Beugelsdijk, S., Slangen, A., Maseland, R., \& Onrust, M. (2014). The impact of home-host cultural distance on foreign affiliate sales: the moderating role of cultural variation within host countries. Journal of Business Research, 67(8), 1638-1646.

* Blomstermo, A., Sharma, D. D., \& Sallis, J. (2006). Choice of foreign market entry mode in service firms. International Marketing Review, 23(2), 211-229.

Brannen, M. Y., \& Doz, Y. (2010). From a distance and detached to up close and personal: bridging strategic and cross-cultural perspectives in international management research and practice. Scandinavian Journal of Management, 26(3), 236-247.

Brock, D., Shenkar, O., Shoham, A., \& Siskovick, I. (2008). National culture and expatriate deployment. Journal of International Business Studies, 39(8), 1293-1309.

* Brouthers, K. D., \& Brouthers, L. E. (2000). Acquisition or greenfield start-up? Institutional, cultural and transaction cost influences. Strategic Management Journal, 21(1), 89-97.

* Brouthers, K. D., \& Brouthers, L. E. (2001). Explaining the national cultural distance paradox. Journal of International Business Studies, 32(1), 177-189.

Brouthers, K. D., \& Hennart, J.-F. (2007). Boundaries of the firm: insights from international entry mode research. Journal of Management, 33(3), 395-425.

* Chang, Y.-C., Kao, M.-S., Kuo, A., \& Chiu, C.-F. (2012). How cultural distance influences entry mode choice: the contingent role of host country's governance quality. Journal of Business Research, 65(8), 1160-1170.

* Chang, S. J., \& Rosenzweig, P. M. (2001). The choice of entry mode in sequential foreign direct investment. Strategic Management Journal, 22(8), 747-776.

* Chari, M. D., \& Chang, K. (2009). Determinants of the share of equity sought in cross-border acquisitions. Journal of International Business Studies, 40(8), 1277-1297.

* Chen, C.-J. (2003). The effects of environment and partner characteristics on the choice of alliance forms. International Journal of Project Management, 21(2), 115-124.

* Chen, H., \& Hu, M. Y. (2002). An analysis of determinants of entry mode and its impact on performance. International Business Review, 11(2), 193-210.

* Cheok J., Hede A.-M., Watne T.A. (2013). Explaining cross-cultural service interactions in tourism with Shenkar's cultural friction. Current Issues in Tourism, 18(6), 1-22.

* Cho, K., \& Padmanabhan, P. (1995). Acquisition versus new venture: the choice of foreign establishment mode by Japanese firms. Journal of International Management, 1(3), 255-285.

* Cho, K. R., \& Padmanabhan, P. (2005). Revisiting the role of cultural distance in MNC's foreign ownership mode choice: the moderating effect of experience attributes. International Business Review, 14(3), 307-324.

* Contractor, F. J., \& Kundu, S. K. (1998). Modal choice in a world of alliances: analyzing organizational forms in the international hotel sector. Journal of International Business Studies, 29(2), 325-357.

Czinkota, M. R., \& Kotabe, M. (2000). Entering the Japanese market: a reassessment of foreign firms' entry and distribution strategies. Industrial Marketing Management, 29(6), 483-491.

* Davidson, W. H., \& McFetridge, D. G. (1985). Key characteristics in the choice of international technology transfer mode. Journal of International Business Studies, 16(2), 5-21.

* Demirbag, M., Glaister, K. W., \& Tatoglu, E. (2007). Institutional and transaction cost influences on MNEs' ownership strategies of their affiliates: evidence from an emerging market. Journal of World Business, 42(4), 418-434.

* Demirbag, M., Tatoglu, E., \& Glaister, K. W. (2008). Factors affecting perceptions of the choice between acquisition and greenfield entry: the case of Western FDI in an emerging market. Management International Review, 48(1), 5-38.

* Demirbag, M., Tatoglu, E., \& Glaister, K. W. (2009). Equity-based entry modes of emerging country multinationals: lessons from Turkey. Journal of World Business, 44(4), 445-462.

* Demirbag, M., Tatoglu, E., \& Glaister, K. W. (2010). Institutional and transaction cost influences on partnership structure of foreign affiliates. Management International Review, 50(6), 709-745.

* Dow, D., \& Ferencikova, S. (2010). More than just national cultural distance: testing new distance scales on FDI in Slovakia. International Business Review, 19(1), 46-58.

* Dow, D., \& Karunaratna, A. (2006). Developing a multidimensional instrument to measure psychic distance stimuli. Journal of International Business Studies, 37(5), 578-602. 
* Dow, D., \& Larimo, J. (2009). Challenging the conceptualization and measurement of distance and international experience in entry mode choice research. Journal of International Marketing, 17(2), 74-98.

* Dow, D., \& Larimo, J. (2011). Disentangling the roles of international experience and distance in establishment mode choice. Management International Review, 51(3), 321-355.

* Drogendijk, R., \& Slangen, A. (2006). Hofstede, Schwartz, or managerial perceptions? The effects of different cultural distance measures on establishment mode choices by multinational enterprises. International Business Review, 15(4), 361-380.

* Elango, B. (2003). Does excess resources influence entry mode decisions of firms: a resource imbalance perspective. Journal of Transnational Management Development, 8(3), 47-69.

* Elango, B. (2005). The influence of plant characteristics on the entry mode choice of overseas firms. Journal of Operations Management, 23(1), 65-79.

* Erramilli, M. K. (1991). The experience factor in foreign market entry behavior of service firms. Journal of International Business Studies, 22(3), 479-501.

* Erramilli, M. K. (1996). Nationality and subsidiary ownership patterns in multinational corporations. Journal of International Business Studies, 27(2), 225-248.

* Erramilli, M. K., Agarwal, S., \& Kim, S.-S. (1997). Are firm-specific advantages location-specific too? Journal of International Business Studies, 28(4), 735-757.

* Erramilli, M. K., \& Rao, C. P. (1993). Service firms' international entry-mode choice: a modified transaction-cost analysis approach. The Journal of Marketing, 57(3), 19-38.

* Estrin S., Ionascu D., Meyer K. (2007). Formal and informal institutional distance, and international entry strategies. William Davidson Institute Working Paper 728. Available at SSRN: http://ssrn. com/abstract $=665110$ or $10.2139 /$ ssrn .665110 .

* Fisher, T. F., \& Ranasinghe, M. (2001). Culture and foreign companies' choice of entry mode: the case of the Singapore building and construction industry. Construction Management and Economics, 19(4), 343-353.

* Fladmoe-Lindquist, K., \& Jacque, L. L. (1995). Control modes in international service operations: the propensity to franchise. Management Science, 41(7), 1238-1249.

* Gatignon, H., \& Anderson, E. (1988). Multinational corporation's degree of control over foreign subsidiaries: an empirical test of a transaction cost explanation. Journal of Law Economics and Organization, 4(2), 305-336.

*Harzing, A.-W. (2002). Acquisitions versus greenfield investments: international strategy and management of entry modes. Strategic Management Journal, 23(3), 211-227.

Harzing, A.-W. (2003). The role of culture in entry mode studies: from negligence to myopia? Advances in International Management, 15, 75-127.

Harzing, A.-W., Reiche, B. S., \& Pudelko, M. (2013). Challenges in international survey research: a review with illustrations and suggested solutions for best practice. European Journal of International Management, 7(1), 112-134.

Harzing, A.-W., \& van der Wal, R. (2008). Google Scholar as a new source for citation analysis? Ethics in Science and Environmental Politics, 8(1), 62-71.

Healy, P. M., \& Palepu, K. G. (1993). International corporate equity associations: who, where, and why? In K. A. Froot (Ed.), Foreign direct investment (pp. 231-254). Chicago: University of Chicago Press.

* Hennart, J.-F., \& Larimo, J. (1998). The impact of culture on the strategy of multinational enterprises: does national origin affect ownership decisions? Journal of International Business Studies, 29(3), 515-538.

Hennart, J.-F., \& Park, Y.-R. (1993). Greenfield vs. acquisition: the strategy of Japanese investors in the United States. Management Science, 39(9), 1054-1070.

* Herrmann, P., \& Datta, D. K. (2002). CEO successor characteristics and the choice of foreign market entry mode: an empirical study. Journal of International Business Studies, 33(3), 551-569.

* Herrmann, P., \& Datta, D. K. (2006). CEO experiences: effects on the choice of FDI entry mode. Journal of Management Studies, 43(4), 755-778.

Hofstede, G. (1980). Culture's consequences, international differences in work-related values. Beverly Hills: Sage.

Hofstede, G. (2001). Culture's Consequences: comparing values, behaviors, institutions and organizations across nations. 2nd edn. Thousand Oaks, CA: Sage Publications. 
* Ionascu D., Meyer K.E., Estrin S. (2004). The concept of "distance" in international business-culture, regulation and cognition - and its relevance to multinationals' entry mode decision. Centre for New and Emerging Markets Discussion Paper Series.

* Kamal, S. (2009). Greenfield vs acquisitions: determinants of choice in emerging economies. BRAC University Journal, 1(2), 63-71.

* Kawai, N., \& Jonas, M. (2009). Market entry strategies in post-financial crisis Southeast Asia: the case of Japanese manufacturing firms. Asian Business and Management, 8(3), 247-275.

* Kim, Y., \& Gray, S. J. (2008). The impact of entry mode choice on foreign affiliate performance: the case of foreign MNEs in South Korea. Management International Review, 48(2), 165-188.

* Kim, Y., \& Gray, S. J. (2009). An assessment of alternative empirical measures of cultural distance: evidence from the Republic of Korea. Asia Pacific Journal of Management, 26(1), 55-74.

* Kim, W. C., \& Hwang, P. (1992). Global strategy and multinationals' entry mode choice. Journal of International Business Studies, 23(1), 29-53.

Kirkman, B. L., Lowe, K. B., \& Gibson, C. (2006). A quarter century of Culture's Consequences: a review of empirical research incorporating Hofstede's cultural values framework. Journal of International Business Studies, 37(3), 285-320.

* Kogut, B., \& Singh, H. (1988). The effect of national culture on the choice of entry mode. Journal of International Business Studies, 19(3), 411-432.

Kopp, R. (1994). International human resource policies and practices in Japanese, European and United States multinationals. Human Resource Management, 33(4), 581-599.

* Larimo, J. (1994). The ownership arrangement decision in foreign direct investments: an empirical study on Finnish subsidiaries in OECD countries. Journal of Euromarketing, 3(1), 75-111.

* Larimo, J. (2003). Form of investment by Nordic firms in world markets. Journal of Business Research, 56(10), 791-803.

* Lee, S., Shenkar, O., \& Li, J. (2008). Cultural distance, investment flow, and control in cross-border cooporation. Strategic Management Journal, 29(10), 1117-1125.

* León-Darder, F., Villar-García, C., \& Pla-Barber, J. (2011). Entry mode choice in the internationalisation of the hotel industry: a holistic approach. The Service Industries Journal, 31(1), 107-122.

Long, G. (2005). China's policies on FDI: review and evaluation. In T. T. Moran, E. M. Graham, \& M. Blomstrom (Eds.), Does foreign direct investment promote development? (pp. 315-336). Washington DC: Institute for International Economics, Centre for Global Development.

* López-Duarte, C., \& Vidal-Suárez, M. M. (2010). External uncertainty and entry mode choice: cultural distance, political risk and language diversity. International Business Review, 19(6), 575-588.

* Luo, Y. (2001). Determinants of entry in an emerging economy: a multilevel approach. Journal of Management Studies, 38(3), 443-472.

Luo, Y., \& Shenkar, O. (2011). Toward a perspective of cultural friction in international business. Journal of International Management, 17(1), 1-14.

* Magnusson, P., Baack, D. W., Zdravkovic, S., Staub, K. M., \& Amine, L. S. (2008). Meta-analysis of cultural differences: another slice at the apple. International Business Review, 17(5), 520-532.

* Majocchi A., Mayrhofer U., Camps J. (2010). The choice between joint ventures and non equityalliances: evidence from Italian firms. In: Proceedings of 36th annual EIBA conference, Portugal.

* Makino, S., \& Neupert, K. E. (2000). National culture, transaction costs, and the choice between joint venture and wholly owned subsidiary. Journal of International Business Studies, 31(4), 705-713.

* Malhotra, S. (2012). Geographic distance as a moderator of curvilinear relationship between cultural distance and shared ownership. Canadian Journal of Administrative Sciences, 29(3), 218-230.

* Martorell, O., Mulet, C., \& Otero, L. (2013). Choice of market entry mode by Balearic hotel chains in the Caribbean and Gulf of Mexico. International Journal of Hospitality Management, 32, 217-227.

Maseland R., van Hoorn A. (2013). Why the institutional distance literature in management is about institutions, not distance. Paper presented at the 55th Annual Meeting of the Academy of International Business, Istanbul.

* Mayrhofer, U. (2004). The influence of national origin and uncertainty on the choice between cooperation and merger-acquisition: an analysis of French and German firms. International Business Review, 13(1), 83-99.

* Morschett, D., Schramm-Klein, H., \& Swoboda, B. (2008). Entry modes for manufacturers' international after-sales service: analysis of transaction-specific, firm-specific and country-specific determinants. Management International Review, 48(5), 525-550. 
* Morschett, D., Schramm-Klein, H., \& Swoboda, B. (2010). Decades of research on market entry modes: what do we really know about external antecedents of entry mode choice? Journal of International Management, 16(1), 60-77.

* Musteen, M., Datta, D. K., \& Herrmann, P. (2009). Ownership structure and CEO compensation: implications for the choice of foreign market entry modes. Journal of International Business Studies, 40(2), 321-338.

* Padmanabhan, P., \& Cho, K. R. (1996). Ownership strategy for a foreign affiliate: an empirical investigation of Japanese firms. MIR Management International Review, 36(1), 45-65.

* Padmanabhan, P., \& Cho, K. R. (1999). Decision specific experience in foreign ownership and establishment strategies: evidence from Japanese firms. Journal of International Business Studies, 30(1), 25-43.

* Pak, Y. S., \& Park, Y.-R. (2004). Global ownership strategy of Japanese multinational enterprises: a test of internalization theory. MIR Management International Review, 44(1), 3-21.

* Pan, Y. (1996). Influences on foreign equity ownership level in joint ventures in China. Journal of International Business Studies, 27(1), 1-26.

* Pangarkar, N., \& Klein, S. (2001). The impacts of alliance purpose and partner similarity on alliance governance. British Journal of Management, 12(4), 341-353.

Pudelko, M. (2006). Universalism, particularism and singularism in cross-national management'. International Studies of Management and Organization, 36(4), 9-37.

Pudelko, M., \& Mendenhall, M. (2009). The contingent nature of best practices in national competitiveness: the case of American and Japanese Innovation process. European Management Journal, 27(6), 456-466.

* Quer, D., Claver, E., \& Rienda, L. (2012). Chinese multinationals and entry mode choice: institutional, transaction and firm-specific factors. Frontiers of Business Research in China, 6(1), 1-24.

* Rajan, K. S., \& Pangarkar, N. (2000). Mode of entry choice: an empirical study of Singaporean multinationals. Asia Pacific Journal of Management, 17(1), 49-65.

* Ramada-Sarasola M. (2009). Entry mode determinants for MNCs going offshore: my 8 million regressions. In: Proceedings of the 8th annual meeting of the EEFS international conference, Warsaw.

* Ramsey, J. R., Barakat, L. L., \& Monteiro, P. R. (2013). Cultural distance and future entry mode choice of Brazilian MNEs. Latin American Business Review, 14(1), 55-78.

Redding, S. G. (2005). The thick description and comparison of societal systems of capitalism. Journal of International Business Studies, 36(2), 123-155.

Ronen, S., \& Shenkar, O. (1985). Clustering countries on attitudinal dimensions: a review and synthesis. Academy of Management Review, 10(3), 435-454.

* Ruiz-Moreno, F., Mas-Ruiz, F. J., \& Nicolau-Gonzálbez, J. L. (2007). Two-stage choice process of FDI: ownership structure and diversification mode. Journal of Business Research, 60(7), 795-805.

* Sanchez-Peinado, E., \& Pla-Barber, J. (2006). A multidimensional concept of uncertainty and its influence on the entry mode choice: an empirical analysis in the service sector. International Business Review, 15(3), 215-232.

Schneider, S. D., \& Barsoux, J. L. (2003). Managing across cultures (2nd ed.). FT Prentice Hall: London.

Selmer, J., Chiu, R., \& Shenkar, O. (2007). Cultural distance asymmetry in expatriate adjustment. Cross Cultural Management, 14(2), 150-160.

* Sengupta, S., \& Perry, M. (1997). Some antecedents of global strategic alliance formation. Journal of International Marketing, 5(1), 31-50.

* Shane S. (1992). The effect of cultural differences in perceptions of transaction costs on national differences in the preference for licensing. Acadamy of Management Best Papers Proceedings, $122-126$.

* Shane, S. (1994). The effect of national culture on the choice between licensing and direct foreign investment. Strategic Management Journal, 15(8), 627-642.

Shenkar, O. (2001). Cultural distance revisited: towards a more rigorous conceptualization and measurement of cultural differences. Journal of International Business Studies, 32(3), 519-535.

Shenkar, O. (2004). One more time: international business in a global economy. Journal of International Business Studies, 35(2), 161-171.

Shenkar, O. (2012). Beyond cultural distance: switching to a friction lens in the study of cultural differences. Journal of International Business Studies, 43(1), 12-17.

Shenkar, O., Luo, Y., \& Yeheskel, O. (2008). From "distance" to "friction": substituting metaphors and redirecting intercultural research. Academy of Management Review, 33(4), 905-923. 
* Slangen, A. H. (2011). A communication-based theory of the choice between greenfield and acquisition entry. Journal of Management Studies, 48(8), 1699-1726.

Slangen A.H., Hennart J.-F. (2001). Greenfield versus acquisition: A critical assessment of the foreign establishment mode literature. Paper presented at the 27 th annual meeting of the European International Business Academy, Paris.

Slangen, A. H., \& Hennart, J. F. (2007). Greenfield vs. acquisition: a review of the empirical foreign establishment mode literature. Journal of International Management, 13(4), 403-429.

* Slangen, A. H., \& Hennart, J.-F. (2008). Do multinationals really prefer to enter culturally distant countries through greenfields rather than through acquisitions? The role of parent experience and subsidiary autonomy. Journal of International Business Studies, 39(3), 472-490.

* Slangen, A. H., \& van Tulder, R. J. (2009). Cultural distance, political risk, or governance quality? Towards a more accurate conceptualization and measurement of external uncertainty in foreign entry mode research. International Business Review, 18(3), 276-291.

Sorge, A. (2005). The global and the local. Understanding the dialectics of business systems. Oxford: Oxford University Press.

* Taylor, C. R., Zou, S., \& Osland, G. E. (1998). A transaction cost perspective on foreign market entry strategies of US and Japanese firms. Thunderbird International Business Review, 40(4), 389-412.

* Tihanyi, L., Griffith, D. A., \& Russell, C. J. (2005). The effect of cultural distance on entry mode choice, international diversification, and MNE performance: a meta-analysis. Journal of International Business Studies, 36(3), 270-283.

* Tsang, E. W. (2005). Influences on foreign ownership level and entry mode choice in Vietnam. International Business Review, 14(4), 441-463.

Tsui, A. S. (2007). From homogenization to pluralism: international management research in the academy and beyond. Academy of Management Journal, 50(6), 1353-1364.

Tung, R. L., \& Verbeke, A. (2010). Beyond Hofstede and GLOBE: improving the quality of crosscultural research. Journal of International Business Studies, 41(8), 1259-1274.

* Vermeulen, F., \& Barkema, H. (2001). Learning through acquisitions. Academy of Management Journal, 44(3), 457-476.

* Villar, C., Pla-Barber, J., \& León-Darder, F. (2012). Service characteristics as moderators of the entry mode choice: empirical evidence in the hotel industry. The Service Industries Journal, 32(7), 1137-1148.

Wang, H., \& Schaan, J.-L. (2008). How much distance do we need? Revisiting the "national cultural distance paradox". Management International Review, 48(3), 263-278.

Werner, S. (2002). Recent developments in international management research: a review of 20 top management journals. Journal of Management, 28(3), 277-305.

Wilson, B. (1980). The propensity of multinational companies to expand through acquisitions. Journal of International Business Studies, 11(1), 59-65.

Woodcock, C., Beamish, P., \& Makino, S. (1994). Ownership-based entry mode strategies and international performance. Journal of International Business Studies, 25(2), 253-273.

* Wu, X., Liu, X., \& Huang, Q. (2012). Impact of the institutional environment on the choice of entry mode: evidence from Chinese enterprises. China An International Journal, 10(1), 28-50.

* Xu, D., Pan, Y., \& Beamish, P. W. (2004). The effect of regulative and normative distances on MNE ownership and expatriate strategies. MIR Management International Review, 44(3), 285-307.

Yiu, D., \& Makino, S. (2002). The choice between joint venture and wholly owned subsidiary: an institutional perspective. Organization Science, 13(6), 667-683.

* Yuehua, X., Songhua, H., \& Xu'ang, F. (2009). The impacts of country risk and cultural distance on transnational equity investments: empirical evidence of Chinese enterprises' shareholdings in overseas listed companies. Chinese Management Studies, 3(3), 235-248.

Zaheer, S., Schomaker, M. S., \& Nachum, L. (2012). Distance without direction: restoring credibility to a much-loved construct. Journal of International Business Studies, 43(1), 18-27.

* Zhao, H., Luo, Y., \& Suh, T. (2004). Transaction cost determinants and ownership-based entry mode choice: a meta-analytical review. Journal of International Business Studies, 35(6), 524-544.

* Zhao, H., \& Zhu, G. (1998). Determinants of ownership preference of international joint ventures: new evidence from Chinese manufacturing industries. International Business Review, 7(6), 569-589. 